DOI: $10.17957 / \mathrm{IJAB} / 15.1889$

http://www.fspublishers.org

\title{
Volatile Organic Compounds of some Antagonists against Lasiodiplodia theobromae, a Pathogen of Coconut
}

\author{
Appusami Sudha ${ }^{* 1}$, Manickam Rajesh ${ }^{1}$, Meiyazhagan Senthil Kumar ${ }^{2}$, Marappagounder Vijayakumar ${ }^{1}$ and Ettiappan \\ Sumathi \\ ${ }^{1}$ Plant Pathology Tamil Nadu Agricultural University Coimbatore, India \\ ${ }^{2}$ Agricultural Entomology, Tamil Nadu Agricultural University, Coimbatore, India \\ ${ }^{3}$ Agronomy, Tamil Nadu Agricultural University, Coimbatore, India \\ *For correspondence: sudhaa1981@gmail.com \\ Received 09 October 2021; Accepted 01 November 2021; Published 15 December 2021
}

\begin{abstract}
Biocontrol agents are the potential microbes and used for the control of aerial and soil-borne pathogens present in all crops. An attempt was made on identification, morphological and molecular characterization of Lasiodiplodia theobromae, a pathogen causing disease in nuts and leaves of coconut. A virulent isolate Lasiodiplodia theobromae L26 was selected based on the growth parameters and pycnidiospore production. Three efficient biocontrol agents (BCAs) namely Trichoderma asperellum, Bacillus subtilis and Streptomyces rochei, were selected for in vitro studies. Among these, T. asperellum showed a significantly higher percentage of inhibition (81\%) in dual culture assay against L26. The inhibition was also confirmed in light microscopic observation, the mycelium of L26 was distorted, lysis of cell wall during the interaction. Volatile organic compounds (VOCs) emitted from BCAs inhibited the fungal growth of L26 by 59.61-47.03\% in sealed plate method. Solid-phase microextraction GC-MS analysis revealed numerous new VOCs compounds emitted from the BCAs, whereas the dominant compound was identified as peptaibols, 2,4-di-tert-butylphenol, 2-piperidinone. The strength of peaks of these compounds augmented during the interaction of BCAs with L26, the peak intensity for terpenoids was the predominant class, followed by phenols and heterocyclic organic compound. Crude metabolite $(75 \mu \mathrm{L})$ of each antagonist tested through agar well method against L26 and showed a complete inhibition. This study demonstrated the ability of BCAs to produce volatile and nonvolatile antifungal compounds, showing that there could a major mechanism involved in and that will be responsible for the successful inhibition of L26 under in vitro. In future combination of these three strains as commercial formulation may be a better management practices for leaf blight and malformation of nuts in coconut. (C) 2021 Friends Science Publishers
\end{abstract}

Keywords: Antifungal compounds; Biocontrol agents; GC-MS; Lasiodiplodia theobromae

\section{Introduction}

Philippines is the second largest country in production, which account for $32.67 \%$ of global production of coconut (Naik 2017). In India, coconut plays an important role in GDP contribution of about 15,000 crore rupees and it accounts $72 \%$ of world production. Tamil Nadu is at the top of the list in the productivity of coconut among the states in India, (CDB-Statistics-area 2018). Coconut, a versatile crop is being used for various uses, but in India, almost $70 \%$ of the coconut is used for the edible purpose. There are several biotic factors which are responsible for the drastic reduction in coconut production and productivity. The major devastating diseases occurring on coconut in Tamil Nadu are bud rot (Phytophthora palmivora), Tanjore wilt or basal stem end rot (Ganoderma lucidum), Kerala wilt (Candidatus phytoplasma), grey blight (Pestalotiopsis palmarum), leaf blight (Lasiodiplodia theobromae) and stem bleeding disease (Thievolopsis paradoxa). Among these, L. theobromae has become severe problem in major coconut growing districts of Tamil Nadu namely, Coimbatore, Erode, Dindigul, Tirunelveli and Kanyakumari which, causes yield losses of 10-25\% (Johnson et al. 2014). The fungus has been act as a secondary infector as the primary factor was due to eriophyid mite (A. guerreronis) and this interaction was studied by Lakshmanan and Jagadeesan (2004). Management of this malady is of immense importance by exploiting the recently reported facts, suitable effective management strategies could be formulated in future from the antagonists. Several biological agents viz., Trichoderma spp., (Ali et al. 2020), Aspergillus spp. Penicillium spp. (Khan and Javaid 2021a, b) Bacillus subtilis, Pseudomonas fluorescens and Streptomyces spp. (Sharf et al. 2021) inhibit phytopathogens growth. It is well known that, Trichoderma spp., are successful biocontrol agents, which produced primary metabolites with antifungal properties to induce resistance (Mukherjee et al. 2012; Khan and Javaid 2020). Macrophomina phaseolina was inhibited by the secondary metabolites of $T$. viride and it was proved

To cite this paper: Sudha A, M Rajesh, MS Kumar, M Vijayakumar, E Sumathi (2021). Volatile organic compounds of some antagonists against Lasiodiplodia theobromae, a pathogen of coconut. Intl J Agric Biol 26:731-740 
by Khan et al. (2021). The plant growth-promoting microbe, Bacillus spp. colonizing the rhizosphere and rhizoplane region, which in turn improves vigour, plant growth and reduce disease incidence. El-Tarabily et al. (2009) and Monteiro et al. (2017) reported that, actinomycetes played an important role in growth promotion when compared to all rhizosphere microbes (Ilic et al. 2007). VOCs produced by $T$. virens control $R$. solani under in vitro, are due to the presence of the antifungal compound viz., $\alpha$-cadinane, docosane and oleic acids were detected in $T$. virens. The n-butanol extract from crude culture of Bacillus spp., showed effective inhibitory activity against $T$. harzianum which is a pathogen observed from mushroom (Fernandes et al. 2019). However, investigations on biopotential of antagonists and the combined interaction with $L$. theobromae are still lacking. So far, not much work has been done on identification of volatile compounds from the BCAs with the pathogens were to be investigated. In recent investigations the potential BCAs were identified and evaluated by the researchers in the department of plant pathology, TNAU, Coimbatore against few pathogens. By using the BCAs, the potent antagonist will be identified under in vitro against $L$. theobromae.

This present study aims to identify the symptomatology, molecular and morphological variations of $L$. theobromae in Tamil Nadu. We employed potential antagonist for screening against the pathogen. FT-IR spectra and Tensor 27 Infrared spectrometer was used for the compound identification and to ascertain the biocontrol effects of volatile blends in antagonists in vitro studies were performed.

\section{Materials and Methods}

\section{Isolation and Selection of virulent isolate}

A survey was conducted in thirty districts of Tamil Nadu to find out the occurrence of both mite and fungal infested nuts to assess the percent incidence, to identify the virulent isolate. Diseased nuts collected from 30 districts of Tamil Nadu during survey were used for the isolation of $L$. theobromae. Isolation and purification of fungal pathogen was carried by hyphal tip transfer procedure (Rangaswami et al. 1975) and incubated at $25 \pm 3^{\circ} \mathrm{C}$ for 7 days (Phipps and Porter 1998). By measuring the culture radial growth, number of pycnidia and pycnidiospore production, virulent isolate of $L$. theobromae, was selected. Molecular identification of $L$. theobromae was carried out by the (CTAB) method described by Ma et al. (2001) and similarity matrix was developed using the Jaccard's coefficient of similarity with the data matrix (Jaccard 1998).

\section{Preparation of media and in vitro antagonistic activity against plant pathogens}

The medium was obtained from Himedia Laboratories (India) was used for culturing fungi (Potato agar medium), nutrient agar medium was used for culturing $B$. subtilis and starch casein agar was used for culturing S. rochei. In addition, the medium (starch casein agar) was added with 25 $\mu \mathrm{g} \mathrm{mL}^{-1}$ nystatin to minimize the fungal contamination. After a week the colonies from antagonistic fungi, bacteria and $S$. rochei were maintained. Antifungal activity screening was studied using potato dextrose agar medium.

\section{Effect on radial mycelial growth by dual culture technique}

The efficacy of antagonistic organisms against the selected $L$. theobromae was tested by dual culture technique (Dennis and Webster 1971). The nine biocontrol strains were obtained from the Culture Collection Centre, Department of Plant Pathology, Tamil Nadu Agricultural University, Coimbatore, Tamil Nadu, India to carry out the study. A nine mm actively growing PDA culture disc of virulent isolate $L$. theobromae was placed onto sterilized PDA medium, previously poured into a sterilized Petridish approximately at a distance of 1.5 $\mathrm{cm}$ away from the periphery of the plate. Similarly, nine $\mathrm{mm}$ culture disc of the respective fungal antagonists viz., $T$. asperellum (Tv1), T. harzianum, T. asperilloides, T. koningeopsis, bacteria viz., Bacillus subtilis (Bs1), B. amyloliquefaciens, B. megatherium, B. lichiniformis and actinobacteria viz., S. rochei were placed onto the medium at the opposite side of the culture plate separately (Dennis and Webster 1971). A plate with pathogen alone on the periphery served as control. Three replications were performed to study the direct efficacy of the antagonist. These plates were inverted and maintained at $28 \pm 2^{\circ} \mathrm{C}$, for five days. Percent inhibition was calculated using the formula:

$$
\mathrm{PI}=\mathrm{C}-\mathrm{T} / \mathrm{C} \times 100
$$

Where PI = percent inhibition; $\mathrm{C}=$ radial growth of the pathogen in the control plate; $\mathrm{T}=$ radial growth of the pathogen in treatment.

During the study of interaction of antagonists with $L$. theobromae culture was placed on slide and stain by lectophenol cotton blue, observed by Digital light microscope at $400 \mathrm{X}$ to study the mode of action.

\section{Inverted plate assay}

Inverted bioassay method was carried out to know the efficacy of antifungal volatiles described by Garbeva $e t a l$. (2014). In this method both the test pathogens and antagonists were inoculated in same plates. To expose the pathogen to the volatile secreted by the antagonists, the test pathogen inoculated plate was placed over the three antagonists, and sealed; these setups were incubated at $28 \pm 2^{\circ} \mathrm{C}$. The growth of hyphae was marked at regular interval and inhibition of pathogen growth was calculated in percentage by comparing with control plate.

Inhibition of fungal growth $=100 \times\left(1-\left(\mathrm{G}_{\mathrm{e}}-\mathrm{G}_{\mathrm{a}}\right)\right)$

$\mathrm{G}_{\mathrm{e}}$-mycelial growth of pathogen in the presence of the antagonists $\mathrm{G}_{\mathrm{a}-\mathrm{m}}$ mycelial growth of pathogen in the absence of the antagonists. 
VOC of S. rochei against Lasiodiplodia / Intl J Agric Biol, Vol 26, No 6, 2021

\section{Preparation of inoculum and fermentation}

The isolated and antifungal tested strains of pathogen, BCAs were taken for this study for inoculums production and fermentation. Yeast molasses broth for $T$. asperellum, King'B broth for B. subtilis, Starch casein agar medium for $S$. rochei and Potato dextrose broth for $L$. theobromae were used for growing the strain for 10 days in $28^{\circ} \mathrm{C}$. The well grown spore suspension was prepared in distilled water for about 10 days. These inoculated broths of bacteria alone were kept in a shaker at $120 \mathrm{rpm}$ at $28^{\circ} \mathrm{C}$ for $3-5$ days as stocks.

\section{Extraction and FT-IR and GC-MS analysis of the antifungal metabolite}

Antifungal metabolites from 7 days old cultures of BCAs were extracted from cell pellets with methanol and also from culture filtrates in ethyl acetate. The extract was dried at $40^{\circ} \mathrm{C}$ using a rotary evaporator and it was suspended in $5 \mathrm{~mL}$ of $1 \%$ HPLC grade methanol (Intana et al. 2005; Vinale et al. 2006). FT-IR spectra were recorded on Bruker, Tensor 27 Infrared spectrometer. GC-MS analysis was performed by using FTIR and GC-MS analysis is used for the analysis of volatile compounds in crude ethyl acetate extract of axenic and coculture of BCAs along with $L$. theobromae was carriedout by trapping them in Tenax $\mathrm{TA}^{\mathrm{TM}}$ coated stainless steel desorbing columns. The crude antibiotics of the effective BCAs were analyzed for the detection of active biomolecules responsible for the suppression of pathogens through GC-MS (GC Clarus 500 Perkin Elmer). Using database searches on the NIST version 2005 MS data library and comparing the spectrum obtained through GC/MS, the compounds present in the crude sample were identified.

\section{Screening of antifungal metabolite against $L$. theobromae}

The diluted metabolite from the antagonists was further tested for their antagonistic property against the fungal pathogen using the agar well diffusion assay. 25, 50, 75 and $100 \mu \mathrm{L}$ crude metabolites of the BCAs were placed inside the PDA wells. The mycelia of the test pathogen were inoculated in with an agar plug of $9 \mathrm{~mm}$ dia. in each plate in the center of the Petridish. The percentage inhibition was studied after 5 days by calculating the inhibition percentage.

\section{Statistical analysis}

The data observed from the above study were analysed using the statistical tool for agricultural Research (STAR 2.0.1). For comparing the treatment means Tukey's honest significance difference test was used, and the significant level of treatment was calculated by the magnitude of the $\mathrm{F}$ value $(P<0.05)$. Plant growth parameters were calculated by the mean \pm standard deviation using GraphPad Prism (v. 6.0) and further comparisons was conducted using DMRT at $P<0.05$ (XLSTAT).

\section{Results}

\section{Survey, isolation and selection of virulent isolate}

A survey was conducted in various districts of Tamil Nadu to assess the occurrence of $L$. theobromae in eriophyid infested coconut. The results of the report revealed that the incidence of $L$. theobromae was varied from 30.60 to 88.12 (PDI) in all districts of Tamil Nadu. Maximum occurrence of the disease was recorded in Vizhupuram (PDI- 88.12), followed by Attur, Salem district (Fig. 1).

The organism grown on PDA and produced a light gray, fluffy and aerial mycelium. The culture became dark in colour in advanced stages. Mycelium was inundated or superficial, branched, septate and brown. Dark brown flask shaped, ostiolate pycnidia appeared in 7-day-old cultures. The ostiole was circular and arranged at the apex of an elongated neck through which pycnidiospore extruded. Pycnidia varied in size, $125-180 \mu \mathrm{m} \times 80-145 \mu \mathrm{m}$. Pycnidiospores were at first hyaline globose to oval and unicellular, but became brown and 1-septate with age and measured 20.5-30.0 $\mu \mathrm{m} \times 11.0-13.5 \mu \mathrm{m}$. Based on characteristics of the pycnidia and pycnidiospores, the fungus was identified as Botryodiplodia theobromae (Pat) syn. Lasiodiplodia theobromae Pat. Griffon \& Maubl (Mullen et al. 1991; Woodward et al. 2005). Maximum No. of pycnidia (90 per plate) with more matured pycnidiospores (65.3) were produced by the isolate L26. The isolate L26 produced highest numbers of pycnidiospore within a short period and it would have the capacity to infect healthy nuts. From this study the isolate L26 was selected for entire studies (Fig. 1). From a total of thirty isolates collected from different places in Tamil Nadu, all the isolates confirmed as L. theobromae by PCR technique (Fig. 2). All the thirty could get an amplification size of approximately $560 \mathrm{bp}$.

\section{In vitro effect of $\mathrm{BCAs}$ on $\mathrm{L} 26$ isolate}

The antagonistic assay was performed using dual plate technique and the radial mycelial growth of the pathogen was monitored. The BCAs, T. asperellum, B. subtilis and $S$. rochei inhibited the mycelial growth of L26 and the percent inhibitions were $67.11,58.49$ and 57.48 respectively, the clear inhibition zone exhibited the antagonistic activity after four days of incubation (Fig. 3). Likewise, other antagonist also inhibited the mycelial growth of the pathogen from 37 to $46 \%$. The spore inhibition percentage also increased from 73.75 to 58.95 (Table 1 and 2). Based on this antagonistic potential the three antagonists were taken for further study. The antagonists also caused extensive hyphal coiling, lysis and thinning respectively and less dense hyphal network compared to control. Light microscopy of the fungal mycelia revealed that distortions, damages and also shrinkage of L26 isolate in the treated plates. In addition, the hyphae were parasitized by spores of the antagonist. In control plate they were no such changes were detected (Fig. 4). 
Table 1: BCAs with their accession Numbers

\begin{tabular}{lll}
\hline Isolate No. & BCAs & Accession number deposited in NCBI \\
\hline 1 & Streptomyces rochei & MT122809 \\
2 & T. asperilloides & Y848322 \\
3 & T. koningeopsis & MF423101 \\
4 & T. harzianum & KX533990 \\
5 & T. asperellum & KX533985 \\
6 & B. subtilis & KF718836 \\
7 & B. amyloliquefaciens & MODE00000000 \\
8 & B. lichiniformis & CP032527.2 \\
9 & B. megatherium & \\
\hline
\end{tabular}

Table 2: In vitro effect of antagonists against radial mycelial growth and spore germination of L26

\begin{tabular}{|c|c|c|c|c|c|}
\hline Sr. No. & Antagonists & $\begin{array}{l}\text { Radial mycelial growth } \\
(\mathrm{mm} *)\end{array}$ & $\%$ growth inhibition over control & $(\%)$ spore germination $*$ & (\%) spore inhibition over control \\
\hline 1 & Trichoderma asperellum & $28.30(38.22)^{\mathrm{a}}$ & 67.11 & $23.25(35.20)^{\mathrm{a}}$ & 73.75 \\
\hline 2 & Bacillus subtilis & $36.00(42.70)^{\mathrm{b}}$ & 58.49 & $32.70(46.66)^{b}$ & 63.45 \\
\hline 4 & Bacillus amyloliquefaciens & $47.90(43.79)^{c}$ & 46.36 & $46.11(42.77)^{\mathrm{cde}}$ & 49.73 \\
\hline 5 & Trichoderma harzianum & $49.80(44.88)^{\mathrm{cd}}$ & 44.23 & $53.47(46.99)^{\mathrm{cd}}$ & 41.71 \\
\hline 6 & Bacillus lichiniformis & $51.10(45.63)^{\mathrm{cd}}$ & 48.78 & $48.85(44.34)^{\mathrm{de}}$ & 46.75 \\
\hline 7 & Trichoderma koningeopsis & $52.00(46.14)^{\mathrm{cd}}$ & 41.77 & $49.87(43.18)^{\text {cde }}$ & 45.63 \\
\hline 8 & Trichoderma asperilloides & $54.00(47.29)^{\mathrm{cd}}$ & 39.53 & $54.52(47.60)^{\mathrm{cde}}$ & 40.56 \\
\hline 9 & Bacillus megatherium & $55.80(48.33)^{\mathrm{cd}}$ & 37.51 & $52.89(46.66)^{\mathrm{e}}$ & 42.34 \\
\hline 10 & control & $89.30(71.47)^{\mathrm{e}}$ & & $91.73(73.30)^{\mathrm{de}}$ & \\
\hline SEd (0.01) & & & 4.23 & & \\
\hline
\end{tabular}

*Mean of three replications.

Values in parantheses are arc sine transformed values.

In a row, means followed by a common letter are not significantly different at $5 \%$ level by DMRT

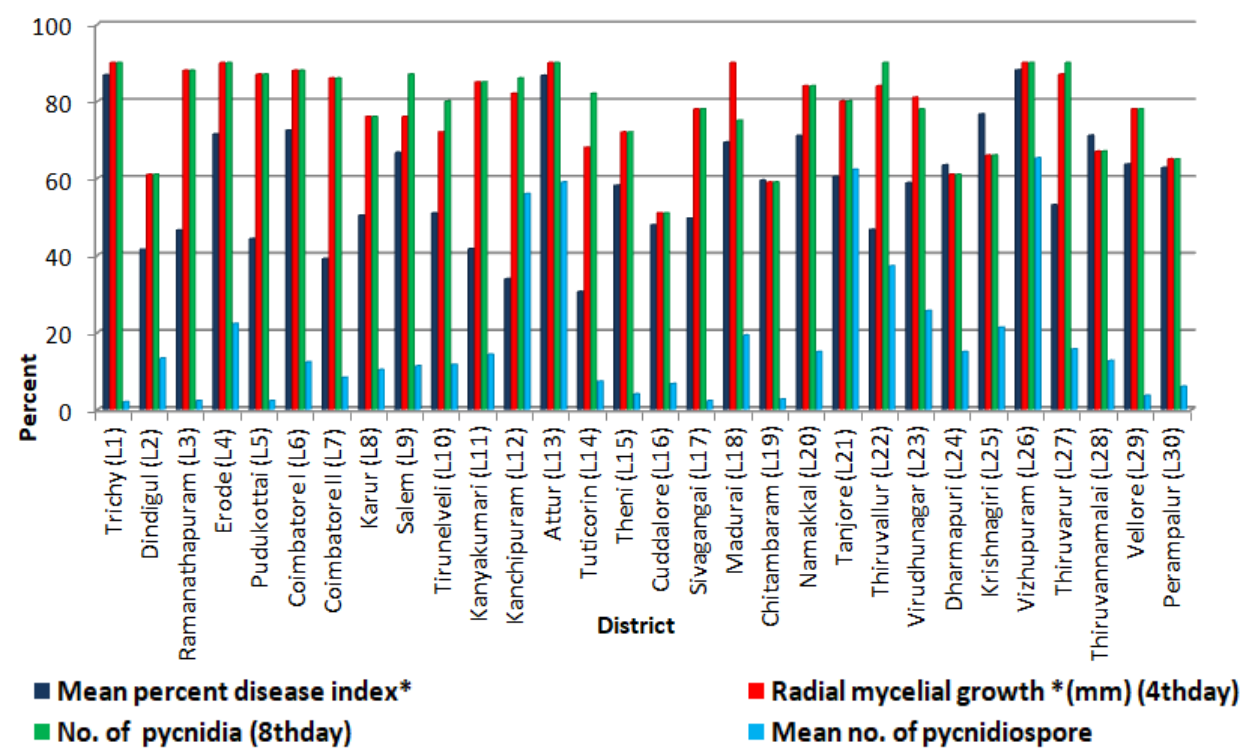

Fig. 1: Prevalence and morphological variation of L. theobromae

\section{Antifungal volatiles test-inverted bioassay}

Antifungal volatiles from the antagonists were studied against L26 using inverted bioassay method. It was noticed that the presence of volatile compounds adversely affect the mycelial growth of $\mathrm{L} 26$ on the $3^{\text {rd }}$ day. There was reduction in percent mycelial growth $(59.61,53.20,47.03 \%)$ in all BCAs compared to control. As support to these results, there was no pycnidia formation in all three test plates where as in control there was increased or more number of pycnidia on day of seventh. The $S$. rochei explored plates had sparse mycelial growth without pycnidia production and there was no inhibition percentage in mycelial growth but reduction in spore formation. The effectiveness of the volatile compounds on the mycelial growth and pycnidia production of the test pathogen proved the suppressing ability of the antagonist under in vitro (Fig. 5). 


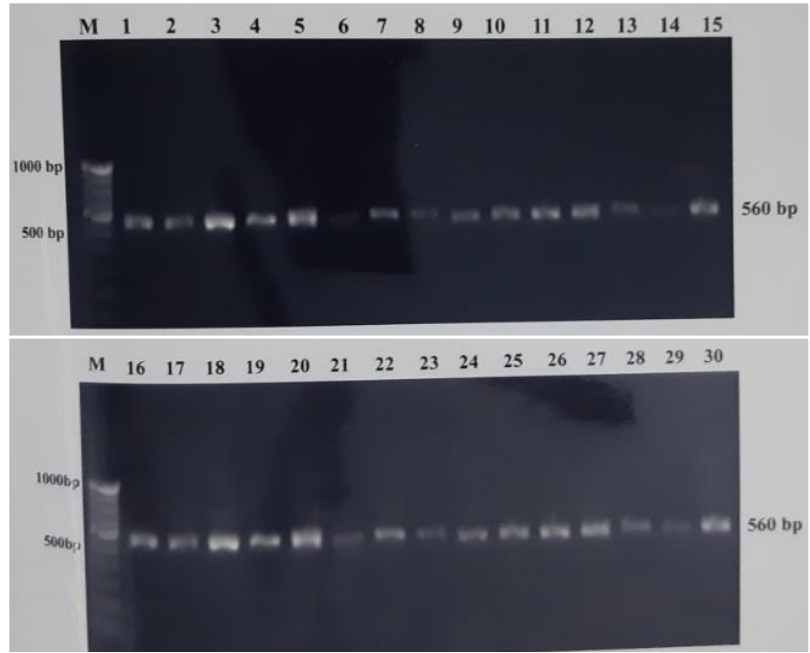

Fig. 2: Agarose gel electrophoresis showing ITS1, 5.8S I and ITS4 ribosomal DNA PCR product of $L$. theobromae

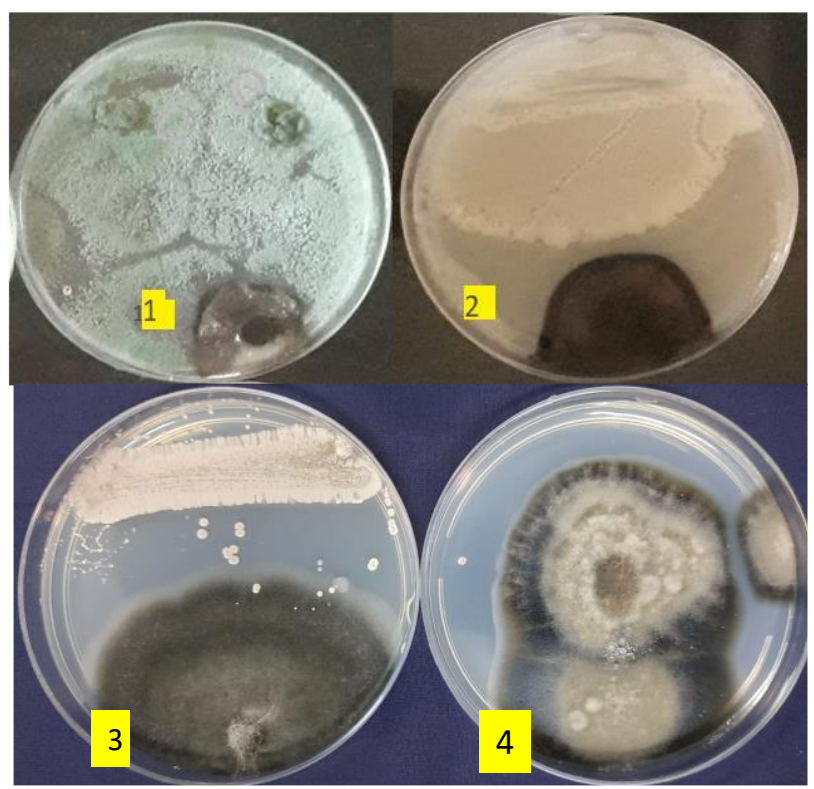

Fig. 3: In vitro effect of $T$. asperellum, B. subtilis and S. rochei against $L$. theobromae

1: T. asperellum vs. L26; 2: B. subtilis vs. L26; 3: S. rochei vs. L26; 4: Control (L26)

\section{Volatilome pattern associated with antagonists with L26 isolate}

The vo latile compounds from the antagonists had an inhibitory effect on L26. Totally, $138 \mathrm{mVOCs}$ were identified, with typical mass spectra and a broad range of molecular weights, ranging 51-492 $\mathrm{g} \mathrm{mol}^{-1}$. The deconvoluted $\mathrm{mVOCs}$ belonged to eighteen classes, the most dominant class is the Benzene derivatives, followed by Heterocyclic organic compound, Terpenoid and Pyrone derivatives and the trend is strong in the interaction of antagonists (Tv, Bs, Sr), with L26 isolate.
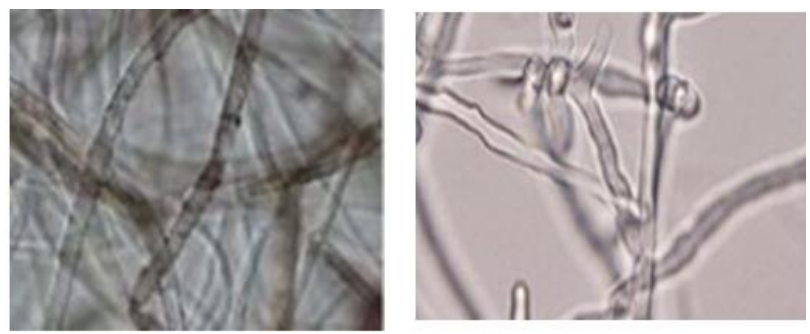

Fig. 4: Light microscopic image of L26 taken at the interaction zone with the antagonists

a. Image of L26 without interaction; b. Hyphal septum malformation and branch deformation during the interaction with antagonists

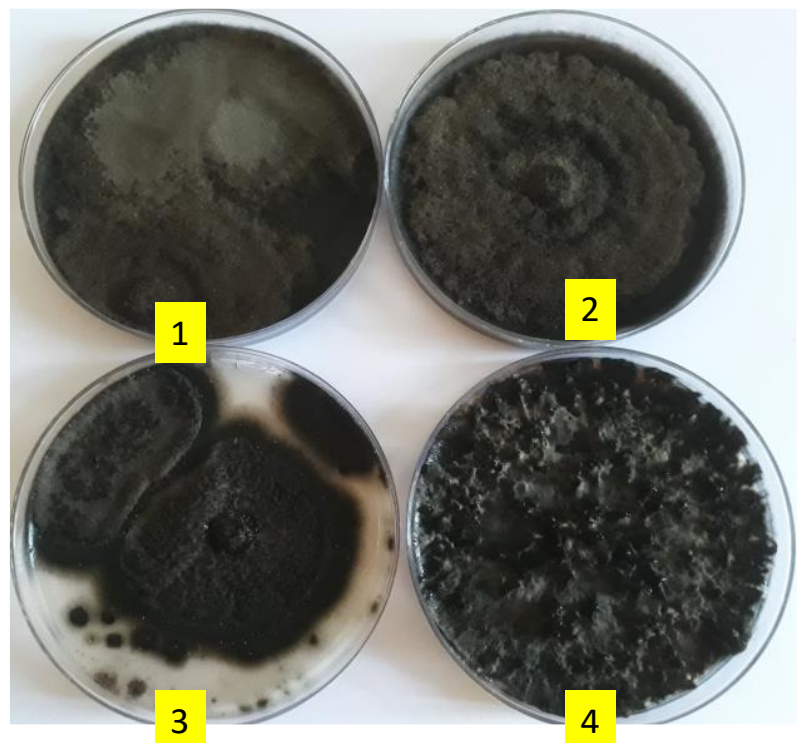

Fig. 5: Effect of volatile metabolites of antagonists on pycnidia formation of L26 isolate

1: T. asperellum vs. L26; 2: B. subtilis vs. L26; 3: S. rochei vs. L26; 4: Control (L26)

GC-MS results revealed that antagonists (Tv) emitted terpenoid compounds ( $\beta$-caryophyllene $(7.667 \%)$ with peak areas, followed by isoamyl alcohol (3-methyl-1-butanol $(15.764 \%)$ and benzene derivatives (1, 2-benzenedicarboxylic acid (22.877\%), 2-butoxy-2-oxoethyl butyl ester (24.655\%). The antagonists $B$. subtilis also emitted benzene derivatives (benzothiazole $(5.192 \%)$, cyclic lipopeptides (surfactin A (9.687\%), saturated hydrocarbons (alkanes $(4.064 \%)$ and $S$. rochei emitted few organic compounds viz., hexahydropyrrolo[1,2-a] pyrazine-1,4-dione (7.655\%), 2-piperidinone (22.876\%), hexahydro-3-(phenylmethyl (15.664\%). The pathogen $L$. theobromae, produces, cyclohexenes and cyclohexenones (4R, 5R)-4,5-dihydroxy-3-methylcyclohex2-enone, theobroxide), jasmonates (methyl jasmonate, (11R)11-hydroxy-jasmonic acid). The intensity of peaks of these compounds increased during the interaction with antagonists with $L$. theobromae the peak intensity for terpenoids ( $\beta$ caryophyllene) was the predominant class, followed by phenols (Ketoconazole) and Heterocyclic organic compound 


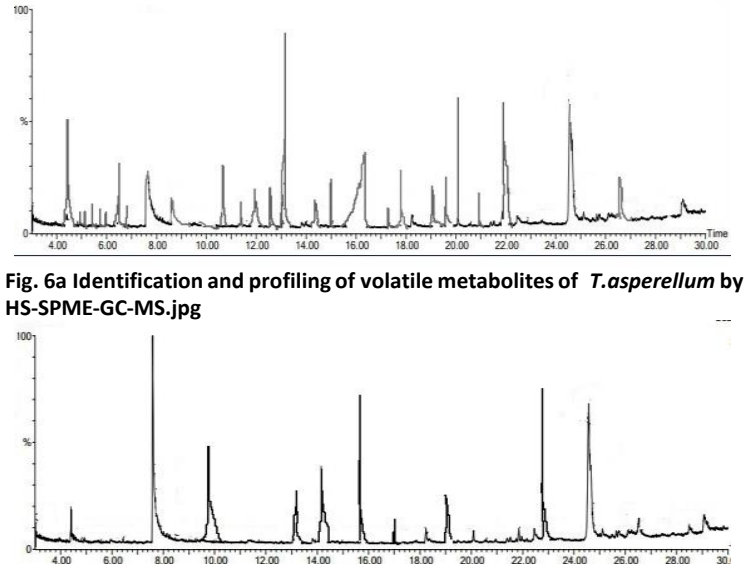

Fig.6c. Identification and profiling of volatile metabolites of S.rochei by HS SPME-GC-MS.jpg

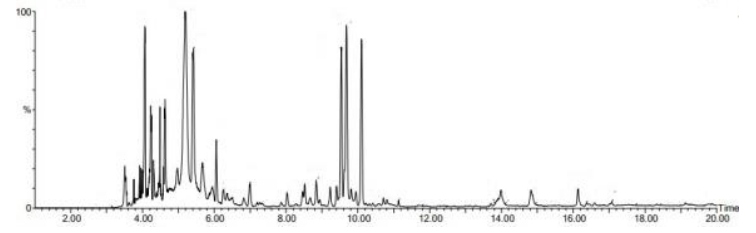

Fig.6b.Identification and profiling of volatile metabolites of B.subtilis by HSSPME-GC-MS.jpg

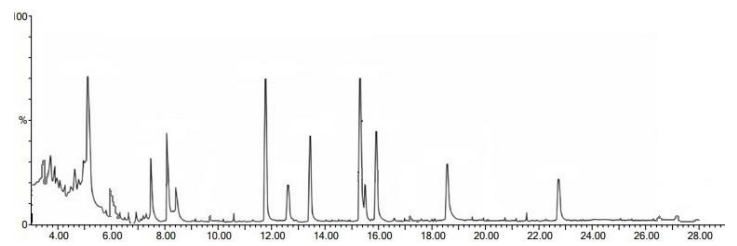

Fig.6d.Identification and profiling of volatile metabolites of L26 by HSSPME-GC-MS.jpg

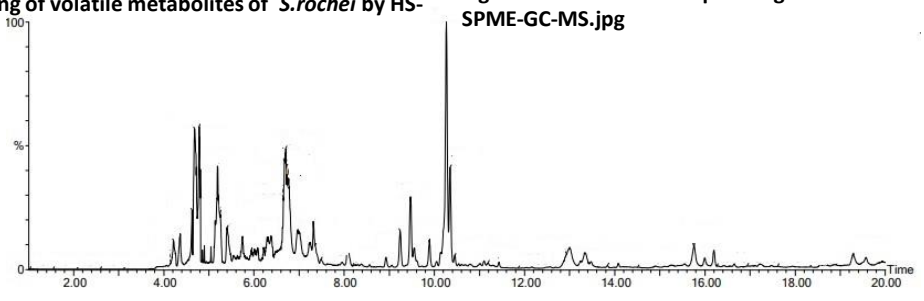

Fig.6e. Identification and profiling of volatile metabolites of $\mathrm{Ta}+\mathrm{Bs}+\mathrm{Sr}+\mathrm{Lt}$ by HS-SPME-GC-MS.jpg

Fig. 6: Identification and profiling of volatile metabolites of antagonists and their interactions by HS-SPME-GC-MS

(2-piperidine) were increased on their interaction (Fig. 6a-e). However, the peak intensity of $5.19 \%$ corresponding to pyrrolo-quinoline derivatives decreased in the interaction of L26 with antagonists (Fig. 8).

\section{Screening of antifungal metabolite against $L$. theobromae}

In agar well diffusion method the metabolites of the three antagonists, showed good antifungal activity against the test pathogen. The dilution from $25 \mu \mathrm{L}$ to $75 \mu \mathrm{L}$ of antimicrobial extract was poured in three replications with a control. The 25 and $50 \mu \mathrm{L}$ of the crude extract from $T$. asperellum inhibited 85.12 and $97.32 \%$ of mycelial growth of L26. There is absolute reduction in mycelial growth at $75 \mu \mathrm{L}$ concentration. The extract from B. subtilis at the concentration of 25 and $50 \mu \mathrm{L}$ showed 86.03 and 95.93 percent mycelial growth. The antagonist $S$. rochei inhibited the mycelia of the pathogen at different concentrations of 25 , 50 and $75 \mu \mathrm{L}$ were $84.09,93.38$ and $100 \%$. At the concentration of $75 \mu \mathrm{L}$ of the extract showed that, complete inhibition in treated compared to control. There was no mycelial growth was observed in $75 \mu \mathrm{L}$ of crude extract treated plates inoculated with L26 (Fig. 7).

\section{Discussion}

For many years, the etiology of the destructive symptom in coconut was deserted by researchers and in spite of the value of this disease, only L. theobromae had been reported as a pathogen to coconut. It causes heavy losses in coconut being a very destructive fungal pathogen worldwide. For the proper identification, distribution, yield loss of the pathogen, the survey was conducted and isolates were collected and validated. Based on the survey report all the isolates were causing the same symptom in coconut with a difference in level of incidence. The pathogen was identified on morphological and molecular basis and identified as $L$. theobromae. The most frequently described morphological characteristics include mycelial growth, pycnidia and pycnidiospore production (Machado et al. 2014; Linaldeddu et al. 2015). Similarly, Ashokkumar et al. (2018) reported that all the isolates showed variation within the morphological characters and the pycnidiospore estimate changes from $14.3 \times 7.69 \mu \mathrm{m}$ (LT-CL2) to $25.59 \times 13.31 \mu \mathrm{m}$ (LT-CL5). Latha et al. (2013) reported that, isolates from Coimbatore (TNAU), showed dark grey colonies and found to be more virulent as it produced maximum pycnidia (63) in $90 \mathrm{~mm}$ Petridish. The virulent was distinguished based on the pathogenicity and production of pycnidiospores under in vitro.

Initially nine BCAs were tested against the fungus, based on the inhibition percentage the three BCAs were selected and they were having highest percentage of inhibition in dual plate assay. It is known that secondary metabolite production, could be strongly influenced the culture growth of the pathogen (Miao et al. 2006). The Different volatile organic compounds from Trichoderma have been profiled with antimicrobial properties and it is 


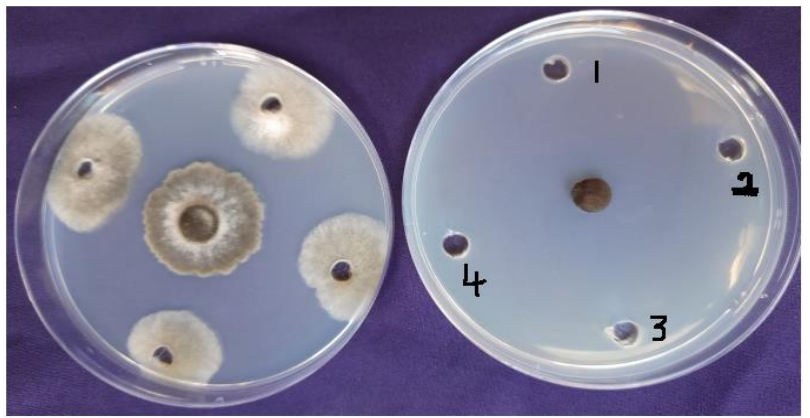

Fig. 7: Effect of extracted metabolites of the antagonists on the radial growth of L26

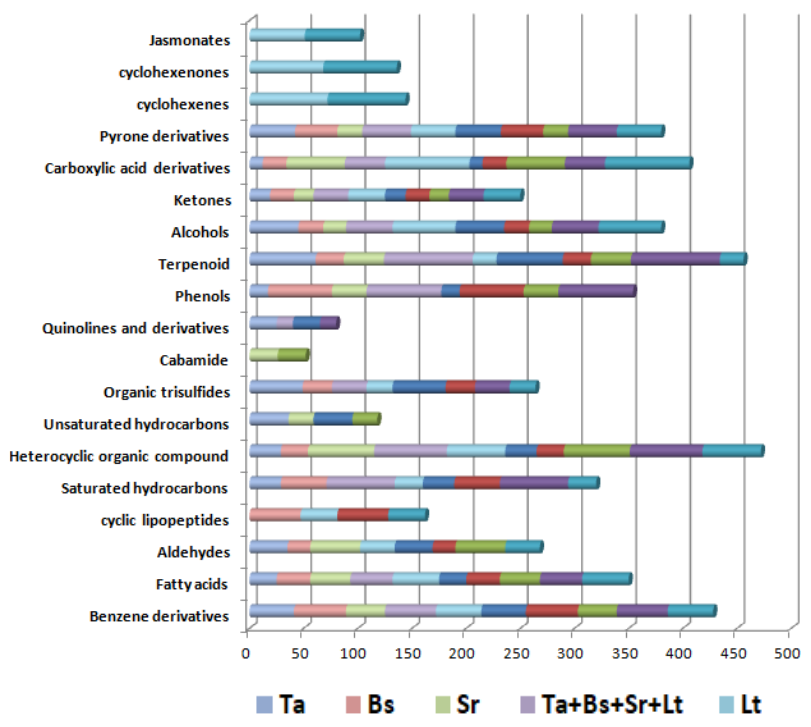

Fig. 8: Compound classes present in axenic and co-culture

specific to different species and strains of Trichoderma (Dennis and Webster 1971). A Bacillus spp. TN79 derived from Thua Nao, suppress the growth of $L$. theobromae (Chukeatirote et al. 2018). Liu et al. (2019) reported that, $S$. sclerotiorum and $R$. solani isolated from soybean root were inhibited by Streptomyces spp. NEAU-S7GS2. Furthermore, Srivastava et al. (2015) described that mycelial formation and percent disease progress of $S$. sclerotiorum was suppressed with $S$. rochei strain SM3 at an approximate rate of $74 \%$. Similarly, Yu et al. (2020) and Martinez et al. (2020) reported that $S$. triticiradicis and $S$. lydicus caused inhibitory effects against pathogenic fungi from 30 to $63 \%$. Hydrolytic enzymes such as chitinases or glucanases or proteases and may be the production of antibiotics against the fungal cell wall of $L$. theobromae was the cause for the zone of inhibition formed by the ultrafiltered crude extracts of BCAs in light microscopic observations (Jain and Jain 2007; Yan et al. 2008; Oskay 2009).

The volatile compounds have an indirect effect, without any contact with between antagonists and pathogen. In this study, there was reduction in percent mycelial growth compared to control and the hyphae regain their development once the antagonists were removed from their atmosphere. This evidence demonstrates that volatile compounds from BCAs are having fungicidal effect and similar results were obtained for sclerotia germination, in the presence of T. reesi, $T$. harzianum, and T. longibrachiatum EF5 the sclerotial germination were reduced in $S$. rolfsii isolates (Sridharan et al. 2020).

In our study, we identified mVOCs with antimicrobial properties from axenic culture of T. asperellum through GCMS-TD such as, peptaibols (aspereline), limonene; $\beta$ eudesmol and 1, 3-octadiene. Wilkins et al. (2003) reported that the metabolite delivered by T. viride (2-propanol, 3methyl furan, 1-pentanol, 2-hexanone), T. atroviride (pentanones, octanones, etc.), T. harzianum (cyclohexane, alcohols, esters etc.) showed hindrance in growth of pathogens and 141 compounds counting a few obscure sesquiterpenes, diterpenes and tetraterpenes from Trichoderma spp. (Lee et al. 2016). The VOCs emitted from B. subtilis was 2, 4-di-tert-butylphenol, also coincides with the results of Ongena and Jacques (2008); Wang et al. (2007) and Yoshida et al. (2001). The large amount antimicrobial activity is attributed to iturin and fengycin was reported by Robacker et al. (1998); Kai et al. (2009) and Caulier et al. (2019). From Bacillus spp. Streptomyces spp. are regarded as noteworthy sources in generation of secondary metabolites and these antimicrobial compounds could play parts in securing plants against distinctive pathogens (Miyada et al. 2017). In our study, S. rochei emitted 2piperidinone and pyrrolo[1,2-a] pyrazine-1,4-dione and few other VOCs. From our investigation, it is observed that the pathogen $L$. theobromae emitted cyclohexenes and cyclohexenones (4R,5R)-4,5-Dihydroxy-3-methylcyclohex2-enone, Theobroxide), jasmonates (Methyl jasmonate, (11R)-11-Hydroxy-jasmonic corrosive) and leads to the restraint of the defense pathway of the plant host, encouraging the disease process (Tsukada et al. 2010; Chanclud and Morel 2016). Few known secondary metabolites, such as jasmonic acid and 3-ICA, phytotoxin scytalone were identified from Lasiodiplodia species (Felix et al. 2018).

Remarkably, our study suggests that several biochemical pathways be drawn in in the construction of VOC in microbes while they relate with one another. These include cis-calamenene related sesquiterpenoids biosynthesis, phenolic malonylglucosides biosynthesis with Terpenophenolic Biosynthesis pathways.

During the interaction experiments, we pragmatic a boost in the expression of volatile compounds. This upregulation of mVOCs might be owed to the existence of diverse genus in the similar culture media. Signal molecules, accountable for the intra- and interspecies communication, are activated throughout these relations. This activation may perhaps be a consequence of more than a few volatile and non-volatile metabolites unconfined during the early development stage by together the microbes. Those 
metabolites were formed from any of the microorganism's viz., BCAs, $L$. theobromae and this verdict was in lineup with the result of Karuppiah and coworkers (2019). Toffolatti et al. (2021) described that terpenoids act as specific or universal pathogen inhibitors. Similarly, in our study during the interaction of BCAs with L26, production of the class terpenenoids was found to be increased and this is one of the responses to assail in several plant-pathogen binomials. As well, phenols (Ketoconazole), act as signaling cursor, organization of arbuscular mycorrhizal symbioses and that can act as agents in plant defense (Mandal et al. 2010) and it is evident from our study during the interaction. Mahmoud and his coworkers also obvious our results that 2-piperidine, a heterocyclic organic compound disrupt the interaction shut between enteric pathogens and these derivatives have a good inhibition capacity against most tested pathogenic bacterial and fungal species due to their potential antimicrobial and fungicidal properties (Mahmoud et al. 2018). Pyrroloquinoline derivatives level is reduced in the coculturing experiments and in assessing redox cycling these derivatives has more than 100 times efficient than polyphenolic compounds, ascorbic acid, isoflavonoids potentials (Stites et al. 2000) and this might be a result of a few unstable and nonvolatile metabolites discharged amid the beginning stage by both the microorganisms. Those metabolites were created from either of the microorganisms viz., T. asperellum, $B$. subtilis, S. rochei, L. theobromae nor interaction of those and this finding was in line with the findings of related proteins, secondary metabolites and plant growth promoting compounds to essentially improve the plant development and assurance against plant pathogens. However, no reports have illustrated the effects of co-cultivating the two most agriculturally important bacteria and fungi along with the pathogen ( $T$. asperellum, B. subtilis, $S$. rochei and $L$. theobromae) on the metabolite production. In this paper, we have tended to this address a few co-cultivation technologies come about in improved action for various secondary metabolites, but frequently not for all.

\section{Conclusion}

Pycnidial producing fungi, $L$. theobromae proved to be a virulent pathogen in coconut and act as secondary pathogen next to eriophyid mite. The BCAs, proved to be effective against $L$. theobromae by producing $\mathrm{mVOCs}$ by inhibiting the pycnidiospore production. The compounds emitted from these BCAs can be deliberate further for additional properties, like growth promotion, medicinal properties, nutrient mobilization etc. Consequently, further it needs to be confirmed by developing a formulation from these biomolecules along with BCAs for more antimicrobial activity. Hence, an active bundling with these substances may be a great alternative to manage the incidence in coconut caused by the dreadful $L$. theobromae. Further, the scale-up of this co-cultivation technology within the fermentor and field study will encourage the use in farming sector.

\section{Acknowledgments}

We greatly thank the colleagues of the department of Plant Pathology, Tamil Nadu Agricultural University, Coimbatore for their support and providing access to the facilities needed for preparation of all the cultures. Additionally, we thank the colleagues from department of Microbiology, for their support and providing access to the facilities needed for the microbiological assays using GCMS.

\section{Author Contributions}

AS, MR and MS conceived the study. AS performed the experiments and analyzed the data. MR coordinated the experiments and helped to draft the manuscript. MS coordinated the experiments related to eriophyid mite. AS, MR and MS drafted the manuscript and wrote R scripts and analyzed the data. All the authors were contributed to the chemical analysis and authentic reference standard measurements. All authors have read and approved the manuscript before submission.

\section{Conflict of Interest}

The authors declare that the research was conducted in the absence of any commercial or financial relationships that could be construed as a potential conflict of interest.

\section{Data Availability}

All datasets presented in this study are included in the article/supplementary material

\section{Funding Source}

Not applicable

\section{References}

Ali A, A Javaid, A Shoaib, IH Khan (2020). Effect of soil amendment with Chenopodium album dry biomass and two Trichoderma species on growth of chickpea var. Noor 2009 in Sclerotium rolfsii contaminated soil. Egypt J Biol Pest Cont 30:1-9

Ashokkumar P, C Ushamalini, R Ramjegathesh (2018). Variations in Morphological and Molecular Characterization of Lasiodiplodia theobromae (Pat.) Griffon and Maubl Associated with Coconut Leaf Blight. Madras Agric J 105:66-71

Caulier S, C Nannan, A Gillis, F Licciardi, C Bragard, J Mahillon (2019). Overview of the antimicrobial compounds produced by members of the Bacillus subtilis group. Front Microbiol 10; Article 302

CDB-Statistics-area (2018). Coconut Development Board, coconutboard.nic.in

Chanclud E, JB Morel (2016). Plant hormones: A fungal point of view. Mol Plant Pathol 17:1289-1297

Chukeatirote E, W Phongtang, J Kim, A Jo, LS Jung, J Ahn (2018). Significance of bacteriophages in fermented soybeans: A review. Biomol Concepts 9:131-142

Dennis C, J Webster (1971). Antagonistic properties of species groups of Trichoderma II. Production of volatile antibiotics. Trans Brit Mycol Soc 37:41-48 
El-Tarabily KA, AH Nassar, GESJ Hardy, K Sivasithamparam (2009). Plant growth promotion and biological control of Pythium aphanidermatum a pathogen of cucumber, by endophytic actinomycetes. $J$ Appl Microbiol 106:13-26

Felix C, M Salvatore, DellaGreca, R Meneses, A Duarte, F Salvatore, D Naviglio, M Gallo, JJ Jorrin-Novo, A Alves, A Andolfi, A Esteves (2018). Production of toxic metabolites by two strains of Lasiodiplodia theobromae, isolated from a coconut tree and a human patient. Mycologia 110:642-653

Fernandes S, S Kerkar, J Leitao, A Mishra (2019). Probiotic Role of Salt Pan Bacteria in Enhancing the Growth of Whiteleg Shrimp, Litopenaeus vannamei. Probiot Antimicrob Proteins 11:1309-1323

Garbeva P, C Hordijk, S Gerards, WD Boer (2014). Volatile-mediated interactions between phylogenetically different soil bacteria. Front Microbiol 5; Article 289

Ilic SB, SS Konstantinovic, ZB Todorovic, ML Lazic, VB Veljkovic, N Jokovic, BC Radovanovic (2007). Characterization and antimicrobial activity of the bioactive metabolites in Streptomycete isolates. Microbiology 76:421-428

Intana $\mathrm{W}$, T Suwanno, C Chamswarng (2005). Use of antifungal metabolite from Trichoderma virens for controlling Chinese kale leaf spots caused by Alternaria brassicicola. Walailak J Sci Technol 2:1-9

Jaccard P (1998). Nouvellers rescherches sur la distribution florate. Bull Soc Vaud Sci Natl 44:223-270

Jain PK, PC Jain (2007). Isolation, characterization and antifungal activity of Streptomyces sampsonii GS 1322. Ind J Exp Biol 45:203-206

Johnson I, B Meena, K Rajamanickam (2014). Biological management of leaf blight disease of coconut using rhizosphere microbes. $J$ Plant Crops 42:364-369

Kai M, M Haustein, F Molina, A Petri, B Scholz, B Piechulla (2009). Bacterial volatiles and their action potential. Appl Microbiol Biotechnol 81:10011012

Karuppiah V, M Vallikkannu, T Li (2019). Simultaneous and sequential based co-fermentations of Trichoderma asperellum GDFS1009 and Bacillus amyloliquefaciens 1841: A strategy to enhance the gene expression and metabolites to improve the bio-control and plant growth promoting activity. Microb Cell Fact 18:1-16

Khan IH, A Javaid (2021a). In vitro screening of Aspergillus spp. for their biocontrol potential against Macrophomina phaseolina. J Plant Pathol 103:1-11

Khan IH, A Javaid (2021b). DNA cleavage of the fungal pathogen and production of antifungal compounds are the possible mechanisms of action of biocontrol agent Penicillium italicum against Macrophomina phaseolina. Mycologia 113: In Press

Khan IH, A Javaid (2020). In vitro biocontrol potential of Trichoderma pseudokoningii against Macrophomina phaseolina. Intl J Agric Biol 24:730-736

Khan IH, A Javaid, D Ahmed (2021). Trichoderma viride controls Macrophomina phaseolina through its DNA disintegration and production of antifungal compounds. Intl J Agric Biol 25:888-894

Lakshmanan P, R Jagadeesan (2004). Malformation and cracking of nuts in coconut palms (Cocos nucifera $\mathrm{L}$.) due to the interaction of the eriophyid mite Aceria guerreronis and Botryodiplodia theobromae in Tamil Nadu, India. J Plant Dis Prot 111:206-207

Latha P, V Prakasam, EI Jonathan, R Samiyappan, C Natarajan (2013). Effect of culture media and environmental factors on mycelial growth and pycnidial production of Lasiodiplodia theobromae in physic nut (Jatropha curcas). J Environ Biol 34:683-687

Lee S, M Yap, G Behringer, R Hung, JW Bennett (2016). Volatile organic compounds emitted by Trichoderma species mediate plant growth. Fung Biol Biotechnol 3; Article 7

Linaldeddu BT, A Deidda, B Scanu, A Franceschini, S Serra, A Berraf-Tebbal, MZ Boutiti, MLB Jamaa, AJL Phillips (2015). Diversity of Botryosphaeriaceae species associated with grapevine and other woody hosts in Italy, Algeria and Tunisia, with descriptions of Lasiodiplodia exiguaandLasiodiplodiamediterraneaspp. nov. Fung Divers 71:201-214

Liu D, R Yan, Y Fu, X Wang, J Zhang, W Xiang (2019). Antifungal, plant growth-promoting and genomic properties of an endophytic actinobacterium Streptomyces spp. NEAU-S7GS2. Front Microbiol 10; Article 2077
Ma Z, EWA Boehm, Y Luo, TJ Michailides (2001). Population structure of Botryosphaeria dothidea from Pistschio and other hosts in California. Phytopathology 91:665-672

Machado AR, DB Pinho, OL Pereira (2014). Phylogeny, identification and pathogenicity of the Botryosphaeriaceae associated with collar and root rot of the biofuel plant Jatropha curcas in Brazil, with a description of new species of Lasiodiplodia. Fung Divers 67:231-247

Mahmoud YG, M Fawy, AE Latif, AA Amra, Osman (2018). Synthesis of newheterocyclic compounds with biological activity against pathogenic microbes in the Albaha area. Biomed J Sci Technol Res 2:2931-2936

Mandal SM, D Chakraborty, S Dey (2010) Phenolic acids act as signaling molecules in plant-microbe symbioses. Plant Signal Behav 5:359-368

Martinez JP, I Mendez, C Ruiz-Esteban, A Fernandez-Sogorb, JM GarciaFernandez (2020). Profiles of burnout, coping strategies and depressive symptomatology. Front Psychol 11; Article 591

Miao L, TFN Kwong, PY Qian (2006). Effect of culture conditions on mycelial growth, antibacterial activity and metabolite profiles of the marine-derived fungus Arthrinium c.f. saccharicola. Appl Microbiol Biotechnol 72:1063-1073

Miyada Z, G Yacine, S Nasserdine, F Mathieu, A Zitouni (2017). Development of formulations based on Streptomyces rochei strain PTL2 spores for biocontrol of Rhizoctonia solani damping-off of tomato seedlings. Biocont Sci Technol 27:723-738

Monteiro CA, JC Moubarac, RB Levy, DS Canella, MLC Louzada, G Cannon (2017). Household availability of ultra-processed foods and obesity in nineteen European countries. Publ Health Nutr 21:18-26

Mukherjee S, V Sushma, S Patra, AK Barui, MP Bhadra, B Sreedhar, CR Patra (2012). Green chemistry approach for the synthesis and stabilization of biocompatible gold nanoparticles and their potential applications in cancer therapy. Nanotechnology 23:1-15

Mullen JM, CH Gilliam, AK Hagan, G Morgan-Jones (1991). Canker of dogwood caused by Lasiodiplodia theobromae, a disease influenced by drought stress or cultivar selection. Plant Dis 75:886-889

Naik JH (2017). Growth trends in area, production and productivity of coconut in major growing countries. IOSR J human Soc Sci 22:47-56

Ongena M, P Jacques (2008). Bacillus lipopeptides: Versatile weapons for plant disease biocontrol. Trends Microbiol 16:115-125

Oskay M (2009). Antifungal and antibacterial compounds from Streptomyces strains. Afr J Biotechnol 8:3007-3017

Phipps PM, DM Porter (1998). Collar rot of peanut caused by Lasiodiplodia theobromae. Plant Dis 82:1205-1209

Rangaswami G, TK Kandasamy, K Ramasamy (1975). Pleurotus sajor-caju (Fr.) Singer-a protein rich nitrogen fixing mushroom fungi. Curr Sci 44:403-444

Robacker DC, AJ Martinez, JA Garcia, RJ Bartelt (1998). Volatiles attractive to the mexican fruit fly (Diptera: Tephritidae) from eleven bacteria taxa. Fla Entomol 81:497-508

Sharf W, A Javaid, A Shoaib, IH Khan (2021). Induction of resistance in chili against Sclerotium rolfsii by plant growth promoting rhizobacteria and Anagallis arvensis. Egypt J Biol Pest Cont 31:1-11

Sridharan AP, T Sugitha, G Karthikeyan, U Sivakumar (2020). Comprehensive profiling of the VOCs of Trichoderma longibrachiatum EF5 while interacting with Sclerotium rolfsii and Macrophomina phaseolina. Microbiol Res 236; Article 1264363

Srivastava S, S Patel, HB Singh, A Sinha, K Sarma (2015). Streptomyces rochei SM3 induces stress tolerance in chickpea against Sclerotinia sclerotiorum and $\mathrm{NaCl}$. J Phytopathol 163:583-592

Stites TE, AE Mitchell, RB Rucker, (2000). Physiological importance of quinoenzymes and the $O$-quinone family of cofactors. $J$ Nutr 130:719-727

Toffolatti SL, G Maddalena, A Passera, P Casati, PA Bianco, F Quaglino (2021). Role of terpenes in plant defense to biotic stress. In: Biocontrol Agents Second Metabol Appl Immun Plant Growth Prot, pp:401-417

Tsukada Y, T Ishitani, KI Nakayama (2010). KDM7 is a dual demethylase for histone H3 Lys 9 and Lys 27 and functions in brain development. Genes Dev 24:432-437

Vinale F, R Marra, F Scala, EL Ghisalberti, M Lorito, K Sivasithamparam (2006). Major secondary metabolites produced by two commercial Trichoderma strains active against different phytopathogens. Lett Appl Microbiol 43:143-148 
Wang J, J Liu, H Chen, J Yao (2007). Characterization of Fusarium graminearum inhibitory lipopeptide from Bacillus subtilis IB. Appl Microbiol Biotechnol 76:889-894

Wilkins K, KF Nielsen, SU Din (2003). Patterns of volatile metabolites and nonvolatile trichothecenes produced by isolates of Stachybotrys Fusarium Trichoderma, Trichothecium and Memnoniella. Environ Sci Pollut Res 10:162-166

Woodward DB, JJH Langston, RC Brock, J Kemerait, TB Brenneman (2005). First demonstration of koch's postulates for Lasiodiplodia theobromae Fruit spot on Eggplant (Solanum melongena). Plant Dis 89:687-687
Yan R, J Hou, D Ding, W Guan, C Wang, Z Wu (2008). In vitro antifungal activity and mechanism of action of chitinase against four plant pathogenic fungi. J Basic Microbiol 48:293-301

Yoshida S, S Hiradate, T Tsukamoto, K Hatakeda, A Shirata (2001). Antimicrobial activity of culture filtrate of Bacillus amyloliquefaciens RC-2 isolated from mulberry leaves. Biol Cont 91:181-187

Yu Z, C Han, B Yu, J Zhao, Y Yan, S Huang, C Liu, W Xiang (2020). Taxonomic Characterization and Secondary Metabolite Analysis of Streptomyces triticiradicis spp. nov, a novel actinomycete with antifungal activity. Microorganisms 8; Article 77 